\title{
Inoculation Method, Temperature, and Relative Humidity Affect Leaf and Neck Anthracnose, a New Onion Disease in Michigan
}

Lina M. Rodriguez-Salamanca, Rachel P. Naegele, Lina M. Quesada-Ocampo, and Mary K. Hausbeck, ${ }^{\dagger}$ Department of Plant, Soil and Microbial Sciences, Michigan State University, East Lansing 48824

Accepted for publication 29 January 2018.

\section{Abstract}

Leaf and neck anthracnose caused by Colletotrichum coccodes is a new disease of onion in Michigan. To test the effect of inoculation method, Prince onion seedlings were grown in the greenhouse and inoculated with either a conidial suspension of $C$. coccodes (alone or with an abrasive agent) or infested millet seed (dry or wet, 2 or $5 \mathrm{~g}$ ). Foliar disease severity was greater when a conidial suspension (>39\%) was used compared with infested millet seed $(\leq 24.3 \%)$. Growth chamber studies were conducted using Infinity onion seedlings that were inoculated with a conidial suspension spray to determine the effects of temperature $\left(15,20,25\right.$, or $\left.30^{\circ} \mathrm{C}\right)$ and duration $(0,12,24,48$, or 72 h) of high $(95 \pm 5 \%)$ relative humidity (RH) on disease severity (percentage of leaf area with $C$. coccodes lesions). Significant differences and interactions among temperature and $\mathrm{RH}$ were observed. The combination of high temperature $\left(\geq 25^{\circ} \mathrm{C}\right)$ and extended ( $\geq 24 \mathrm{~h}$ ) high $\mathrm{RH}$ resulted in $>20 \%$ disease severity 28 days postinoculation. Results suggest that onion leaf and neck anthracnose symptoms are likely to be more severe when the environmental conditions are $\geq 25^{\circ} \mathrm{C}$ with $\geq 24 \mathrm{~h}$ of high $\mathrm{RH}$.
In 2015, 58,518 ha of onions (Allium cepa L.) were planted in the United States with a crop value of $\$ 1.0$ billion (Anonymous 2017). Onions generated \$10.1 million in revenue for Michigan growers in 2015 (Anonymous 2017). Pungent onions are the mainstay of the Michigan industry; the state ranked seventh nationally after California, Washington, Oregon, Idaho, New York, and Colorado and Wisconsin in production of summer storage onion in 2015 (Anonymous 2017).

Colletotrichum coccodes (Wallr.) Hughes was recently reported as a new pathogen on onion foliage in Michigan and the United States (Rodriguez-Salamanca et al. 2012). C. coccodes causes elliptical lesions on onion foliage and pseudostems (neck). Initially, lesions appear sunken and light green to bleached in color with a distinct center. Over time, the center of the lesion may develop a color ranging from salmon to dark brown. Although $C$. coccodes has been reported to cause disease on 50 different hosts worldwide and 18 hosts within the United States (Farr and Rossman 2013), it is best known for causing significant economic and yield losses on solanaceous hosts (Dillard 1992; Tsror [Lahkim] and Johnson 2000). In potato, C. coccodes resulted in a 16 to $30 \%$ reduction in tuber size (Lees and Hilton 2003; Nitzan et al. 2006a, 2008). In tomato, C. coccodes caused 30 to $70 \%$ fruit rot when fungicide sprays were not applied to manage anthracnose (Byrne et al. 1997). The extent of the damage this pathogen can cause on onion has not been previously reported.

Environmental factors conducive to the development of anthracnose disease in onion have not been investigated. In tomato,

\section{${ }^{\dagger}$ Corresponding author: Mary K. Hausbeck; E-mail: hausbec1@msu.edu}

This work was supported by Michigan State University Project GREEEN, Award GR11-030, "New Colletotrichum diseases of Michigan onion and celery"; USDA NIFA Specialty Crops Research Initiative 2010-51181-21192/G-1414-1 under subaward 2010-1365-07, "ipmPIPE and innovative disease diagnostic tools for onion growers"; and the Michigan Onion Committee. L. Quesada-Ocampo was supported by NIFA/USDA project NC02418.

(C) 2018 The American Phytopathological Society
C. coccodes infection and lesion formation occurred when conditions included $\geq 10 \mathrm{~h}$ of high humidity and temperatures ranged from 15 to $31^{\circ} \mathrm{C}$ (Dillard 1989; Kendrick and Walker 1948); optimal lesion development occurred at $27^{\circ} \mathrm{C}$ (Dillard 1988, 1989; Kendrick and Walker 1948). Byrne et al. (1998) studied C. coccodes foliar infection in tomato using a conidial suspension and determined that temperatures of 20 and $25^{\circ} \mathrm{C}$, in combination with 12 and $16 \mathrm{~h}$ of continuous leaf wetness, were most favorable for disease development. Foliar infection of pepper was favored by a temperature of $28^{\circ} \mathrm{C}$ and a wetness period longer than $24 \mathrm{~h}$ (Hong and Hwang 1998). In pepper, foliar symptoms were most severe when foliage was inoculated using a $C$. coccodes conidial suspension compared with a soil drench (Hong and Hwang 1998). Potato foliage inoculated with a $C$. coccodes conidial suspension or a sclerotial suspension resulted in severe foliar symptoms and yield reduction (Johnson 1994; Johnson and Miliczky 1993; Mohan et al. 1992); and foliar infection was favored by wetness periods $>24 \mathrm{~h}$ (Johnson and Miliczky 1993).

Since $C$. coccodes was first detected in Michigan onion fields in 2010 , onion leaf and neck anthracnose has been observed annually to varying degrees within the state. This new foliar disease can increase management costs, thereby reducing profits for Michigan onion growers. To develop a comprehensive management strategy that limits onion leaf and neck anthracnose, studies on the environmental conditions conducive to $C$. coccodes infection and disease progression on onion necks and foliage are needed. We aimed to develop an optimal inoculation method for $C$. coccodes on onion and determine the effects of temperature and the duration of high relative humidity $(\mathrm{RH})$ on onion anthracnose severity.

\section{Plant Culture and Inoculation}

Cultivars Prince (Bejo, Oceano, CA) and Infinity (Nunhems, Parma, ID) onion seedlings were used for inoculation studies and to determine the effect of temperature and the duration of high $\mathrm{RH}$ on C. coccodes severity, respectively. Onion seeds were planted into 
SUREMIX perlite medium (Michigan Grower Products, Galesburg, $\mathrm{MI})$ in 288 -cell flats $(12 \times 24 \times 4.5 \mathrm{~cm})$. Onion seedlings were transplanted into $10-\mathrm{cm}$ diameter pots $\left(387 \mathrm{~cm}^{3}\right)$ when plants were at the 3-leaf stage. The seedlings were grown for 14 days in the greenhouse $\left(25 \pm 2^{\circ} \mathrm{C}, 15\right.$-h photoperiod) where they were watered as needed and fertilized weekly with 20-20-20 fertilizer (Scotts Company, Marysville, $\mathrm{OH}$ ) and full-strength Hoagland's solution (Hoagland and Arnon 1950).

Prior to inoculation, onion seedlings were exposed to a high-RH treatment $(95 \pm 5 \%)$ in enclosed bags for $16 \mathrm{~h}$. Pots containing the seedlings were placed inside 7.5-liter clear plastic bags with $350 \mathrm{ml}$ of water on a 13-cm saucer to keep plants from coming into direct contact with the water. A handmade wire frame placed inside of the bag kept the foliage of the onion plants from coming into direct contact with the surface of the bag.

A mixture of six $C$. coccodes isolates obtained from onion foliage in 2010 was used for the experiments. The isolates originated from various counties in Michigan: 7-1-1-3 (Newaygo Co.), 8-1-1-1 (Ottawa Co.), 24-1-1-2 (Ionia Co., NRRL accession number 62808), 31-1-2-2 (Calhoun Co.), 34-1-6-1 (Kent Co.), and 38-1-3-1 (Eaton Co., NRRL accession number 62809). Isolates were transferred from long-term storage onto $50 \%$ strength potato dextrose agar and maintained at $22 \pm$ $2{ }^{\circ} \mathrm{C}$ under fluorescent light. The methods used in inoculation experiments included (i) a conidial suspension spray, (ii) a conidial suspension spray mixed with an abrasive agent, (iii) a conidial suspension applied as a soil drench, (iv) infested millet seed subjected to a drying process (dry), and (v) infested millet seed not subjected to a drying process (wet).

To prepare the conidial suspension, 7-day-old cultures of C. coccodes were flooded with $1.0 \mathrm{ml}$ of sterile double-distilled water with $0.001 \%$ Tween. Conidia were dislodged with a sterile tongue depressor. The conidial suspension was filtered through three layers of sterile cheesecloth. The concentration was determined using a hemocytometer, and the suspension was adjusted to $2.0 \times 10^{5}$ conidia/ml using sterile double-distilled water with $0.001 \%$ Tween. Equal volumes of conidial suspensions per isolate were mixed, and the resulting combination was used to inoculate the onion seedlings. When diatomaceous earth was used as an abrasive agent with a conidial suspension, the $0.001 \%$ Tween water was amended with $0.001 \%$ (w/v) Concern Diatomaceous Earth (Woodstream, Lititz, PA).

The millet seed inoculum was prepared by mixing $100 \mathrm{~g}$ of millet seed and $15 \mathrm{ml}$ of water in a glass flask and autoclaving in two consecutive cycles. Eight $0.7-\mathrm{cm}$ plugs of 7-day-old C. coccodes mycelium were used to inoculate the millet seed. Two flasks per isolate were infested and incubated at $22 \pm 2^{\circ} \mathrm{C}$ under constant fluorescent lights for 15 days. Following incubation, a portion of the millet was transferred into sterile paper bags and dried for 3 days at $26 \pm 2{ }^{\circ} \mathrm{C}$ and then spread onto a sterile tray and allowed to dry in a flow hood for 2 days to induce formation of microsclerotia. Ten grams of infested millet from each isolate was mixed together for the $C$. coccodes millet seed inoculum (either dried or wet) and applied to the onion seedlings for evaluation.

Greenhouse experiments were conducted to determine the effect of different inoculation methods on disease progression. The experiment consisted of five inoculation methods with five plants (experimental units) per method as previously described. Inoculation methods were tested in a complete randomized design and repeated once. A conidial suspension with or without the abrasive agent was sprayed onto the onion canopy ( $2 \mathrm{ml} / \mathrm{plant})$ using an airbrush (T63 Vega 2000, Badger Air-Brush, Franklin Park, IL). For the soil drench inoculation, $10 \mathrm{ml}$ of conidial suspension was applied to the base of the onion seedlings. Two or five grams of the C. coccodes-infested millet seed, dried or wet, was placed around the base of the onion seedlings. Control plants were treated with their respective treatment minus the pathogen. Following inoculation, plants were returned to high RH $(95 \pm 5 \%)$ for $72 \mathrm{~h}$ using plastic bags with a wire frame as described previously. After the 72-h treatment, bags were opened and plants were removed from the bags and placed on 13-cm saucers, where they were watered twice each week by adding water to the saucer to avoid water splash.

\section{Growth Chamber Experiments}

Experiments were conducted to determine the effect of temperature and duration of high-RH treatments on onion leaf and neck anthracnose severity. Growth chambers (model CMP3244, Conviron, Pembina, ND) were set at $15,20,25$, or $30^{\circ} \mathrm{C}$ with a $16 / 8$-h photoperiod and $95 \mathrm{mE}$ of light intensity. Infinity onion seedlings were moved into each of the four growth chambers in a randomized split plot design. In the design, temperature was the whole plot and the duration of high-RH treatment was the subplot. The durations of high-RH $(95 \pm 5 \%)$ treatments tested were $0,12,24,48$, and $72 \mathrm{~h}$. The experiment had two experimental units (two plants) per temperature and $\mathrm{RH}$ treatment combination, and it was conducted three times. Onion seedlings were sprayed with a conidial suspension consisting of a mixture of $C$. coccodes without abrasive agent (as previously described). To achieve high $\mathrm{RH}$, seedlings were incubated in a plastic bag with a wire frame as described above and placed inside growth chambers at their randomly assigned temperature. Plants assigned to the 0-h high-RH treatment were not bagged after inoculation. A watchdog sensor (Spectrum Technologies, Plainfield, IL) was placed inside each growth chamber and within the bag to monitor temperature and RH.

Each leaf was evaluated for severity by visually assessing the area (\%) covered with $C$. coccodes lesions, using a scale from the leaf blotch of cereals assessment key 1.6.1 (James 1971). Disease was assessed 4, 7, 14, 21, and 28 days after inoculation (DAI). The area under the disease progress curve (AUDPC) was calculated using the average severity rating per plant. At the conclusion of each experiment, $10 \%$ of the plants were randomly selected and the pathogen isolated from symptomatic tissue to verify $C$. coccodes as the causal agent. The resulting fungal colonies were confirmed as C. coccodes based on colony appearance and morphology of conidia at $400 \times$ magnification with a compound microscope (Robert et al. 2005; Sutton 1980).

The PROC MIXED procedure in the SAS statistical analysis software version 9.2 (SAS Institute, Cary, NC) was used to test the main effects in all experiments. Logarithmic transformation was conducted to fulfill normal distribution and homogeneity of variance assumptions. ANOVA was performed using the type III test for fixed effects output. Significant differences $(P<0.05)$ were subject to grouping by least significant differences (LSD) per effect (inoculation method, temperature, and high $\mathrm{RH}$ ). For temperature and RH experiments, significant interactions in the split plot design were sliced by effect and grouping by LSD with an $\alpha$ of 0.05 .

\section{Comparison of Inoculation Methods and RH and Temperature Effects}

All inoculation methods tested resulted in neck and leaf anthracnose symptoms on Prince onion seedlings, and control plants remained asymptomatic. Lesions developed 7 DAI, were oval shaped, and were approximately $2 \mathrm{~mm}$ wide $\times 3 \mathrm{~mm}$ long with a light tan or bleached center. Lesions expanded and coalesced, and salmon-colored sporulation was observed from 14 to $28 \mathrm{DAI}$ across inoculation method treatments. Lesions first occurred on leaves when inoculated with a conidial spray (with or without an abrasive agent); lesions developed first on the necks when plants were 
inoculated either with the conidial suspension soil drench or infested millet.

AUDPC data indicated significant differences among inoculation methods $(P<0.0001$, Table 1$)$. Mean AUDPC values were highest for conidial spray inoculations, which were similar regardless of an abrasive agent additive (Table 1). Inoculating seedlings with a conidial soil drench resulted in a significantly lower mean AUDPC value than using a conidial spray with an abrasive agent but was similar to plants inoculated with a conidial spray alone. Plants inoculated with C. coccodes-infested millet seed (either dry or wet) had reduced mean AUDPC values when compared with plants inoculated with a conidial spray or soil drench. Sclerotia were abundant within the millet that was subjected to the drying process, whereas the infested millet seed inoculum that was not dried consisted of mycelia and conidia (data not shown). There were no significant differences between mean AUDPC values for millet amounts ( 2 or $5 \mathrm{~g}$ ) or millet water content (dry or wet) (Table 1). Final disease incidence of onion seedlings was highest (39\%) for plants inoculated with a conidial suspension with or without an abrasive agent and was not significantly different from plants inoculated with a conidial soil drench (30\%). Final disease severity was lower for onion seedlings inoculated with infested millet regardless of water content or inoculum quantity, ranging from a low of 19.0 to a high of $24.3 \%$ for dry $(2 \mathrm{~g})$ and wet $(2 \mathrm{~g})$ millet, respectively (Table 1).

Sunken oval lesions were observed 7 DAI on $C$. coccodesinoculated Infinity onion seedlings following incubation at high $\mathrm{RH}$ for $24 \mathrm{~h}$ or longer at temperatures $20^{\circ} \mathrm{C}$ or greater (Fig. 1). Disease progressed when high $\mathrm{RH}$ exceeded $12 \mathrm{~h}$ and temperatures exceeded $20^{\circ} \mathrm{C}$ (Fig. 1). Significant differences were observed for mean AUDPC values among duration of high-RH treatments $(P<$ $0.0001)$ and temperatures $(P=0.0081$, Table 2$)$. Increased mean AUDPC values were observed at increased durations of high $\mathrm{RH}$; AUDPC values were significantly lower for $12 \mathrm{~h}$ of high $\mathrm{RH}$ than treatments of 24,48 , and $72 \mathrm{~h}$. There were no significant differences in mean AUDPC values between 24 and $48 \mathrm{~h}$ or between 48 and $72 \mathrm{~h}$ of high $\mathrm{RH}$, but the difference between 24 and $72 \mathrm{~h}$ was significant. Mean AUDPC values were significantly increased for inoculated onions incubated at higher temperatures $\left(25\right.$ and $\left.30^{\circ} \mathrm{C}\right)$ compared with lower temperatures $\left(15\right.$ and $\left.20^{\circ} \mathrm{C}\right)$ (Table 2).

There was a significant temperature and high-RH treatment interaction for mean AUDPC values $(P<0.0001)$. At $15^{\circ} \mathrm{C}$, AUDPC values were not significantly different among high-RH-duration

\begin{tabular}{|c|c|c|}
\hline \multicolumn{3}{|c|}{$\begin{array}{l}\text { TABLE } 1 \\
\text { Effect of inoculation method on the area under the disease } \\
\text { progress curve (AUDPC) and final onion leaf and neck } \\
\text { anthracnose severity on Prince onion seedlings inoculated } \\
\text { with Colletotrichum coccodes }\end{array}$} \\
\hline Inoculation method & Mean AUDPC & Final (\%) \\
\hline Conidial spray with abrasive agent & $728.2 \mathrm{a}^{\mathrm{x}}$ & $39.3 \mathrm{a}$ \\
\hline Conidial spray alone & $698.1 \mathrm{ab}$ & $39.2 \mathrm{a}$ \\
\hline Soil drench & $514.0 \mathrm{~b}$ & $30.6 \mathrm{ab}$ \\
\hline Dry ${ }^{\mathrm{y}}$ millet $(5 \mathrm{~g})$ & $146.3 \mathrm{c}$ & $23.7 \mathrm{~b}$ \\
\hline Dry millet (2 g) & $232.1 \mathrm{c}$ & $24.3 \mathrm{~b}$ \\
\hline Wet $^{\mathrm{z}}$ millet $(5 \mathrm{~g})$ & $133.7 \mathrm{c}$ & $23.3 \mathrm{~b}$ \\
\hline Wet millet $(2 \mathrm{~g})$ & $172.6 \mathrm{c}$ & $19.0 \mathrm{~b}$ \\
\hline
\end{tabular}

${ }^{x}$ Means within a column for inoculation method followed by the same letter are not significantly different (LSD), $\alpha=0.05$.

${ }^{\mathrm{y}}$ Infested millet seed subjected to drying process, 5 or $2 \mathrm{~g}$ used for inoculation

${ }^{\mathrm{z}}$ Infested millet seed not subjected to drying process, 5 or $2 \mathrm{~g}$ used for inoculation. treatments (Fig. 2). At $20^{\circ} \mathrm{C}$, the mean AUDPC value for $72 \mathrm{~h}$ was significantly higher than 0 and $12 \mathrm{~h}$, but similar to 24 and $48 \mathrm{~h}$. At 25 and $30^{\circ} \mathrm{C}$, treatments of 24,48 , and $72 \mathrm{~h}$ of high $\mathrm{RH}$ had similar mean AUDPC values that were higher than the AUDPC values of the 0 and $12 \mathrm{~h}$ high-RH treatments.

For both studies, the plants randomly selected for reisolation exhibited lesions that contained acervuli and setae when observed under the dissecting scope. Five to seven days after symptomatic tissue was sampled, fungal colonies exhibited salmon coloration, with production of cylindrical conidia ( 17 to $22 \times 2.8$ to $4.0 \mu \mathrm{m}$ in size) and black microsclerotia 14 days later. All colonies matched C. coccodes morphological characteristics of the isolates used for inoculation.

\section{Conclusions and Management Implications}

In Michigan, onion leaf and neck anthracnose, caused by C. coccodes, was initially observed in 2010 in six counties
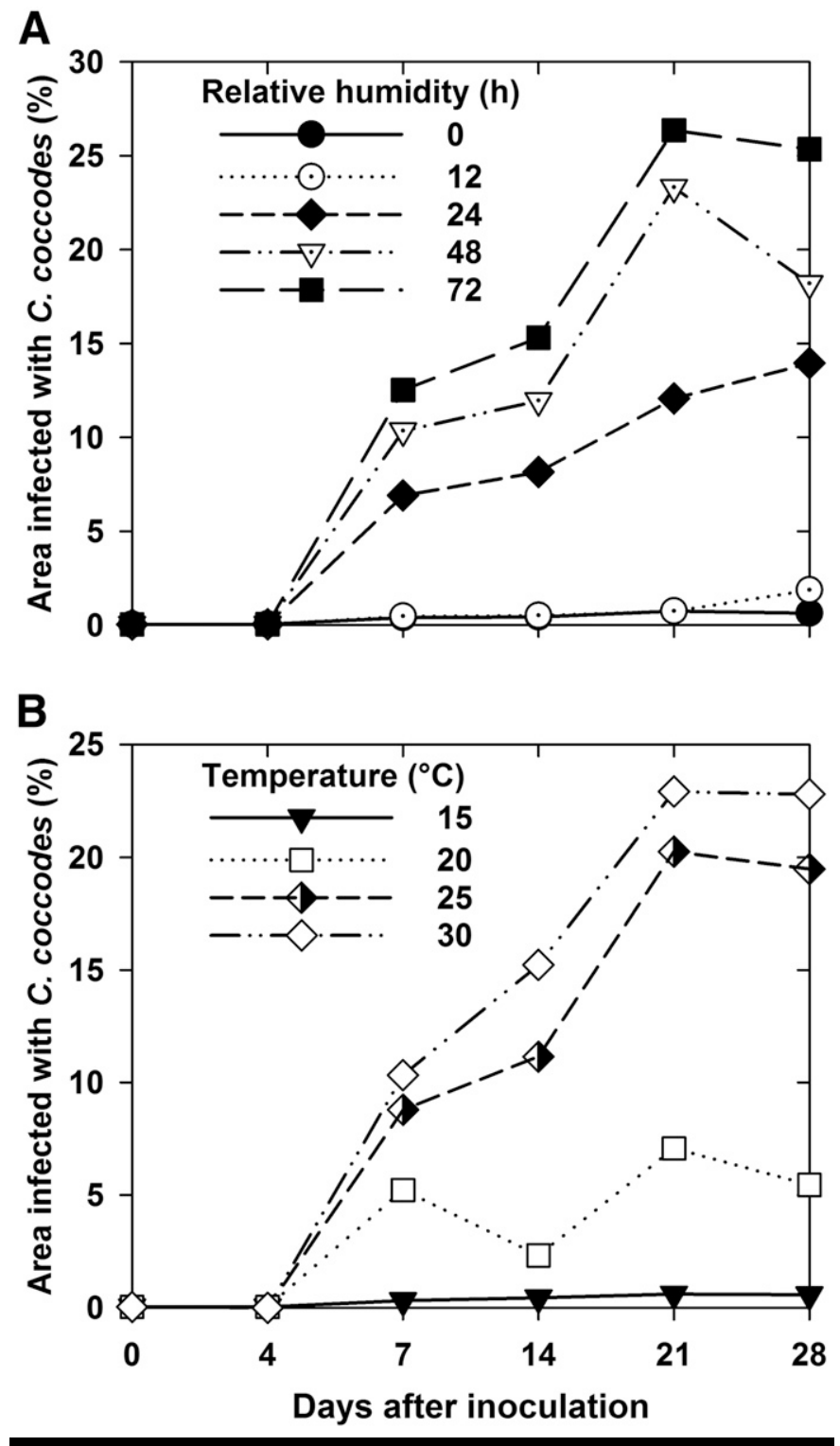

FIGURE 1

Effect of duration of high relative humidity (A) and temperature (B) on disease severity over time for onion leaf and neck anthracnose on Infinity onion seedlings inoculated with Colletotrichum coccodes. 
(Rodriguez-Salamanca 2013) and has continued to occur to some degree each year thereafter. By determining the effect of inoculation method, temperature, and duration of high-RH treatment on onion leaf and neck anthracnose disease severity, we sought to better understand the pathogen to develop a foundation for future management studies and guide growers.

Inoculation method affected anthracnose progression and severity. When a conidial suspension was applied to onions as a foliar spray or soil drench, the resulting disease severity did not differ, similar to studies with pepper (Hong and Hwang 1998). In pepper, soil drench inoculation resulted in damping off of 2-leaf seedlings (Hong and Hwang 1998), but damping off was not observed in the present study with onion seedlings. Inoculation with a conidial suspension amended with an abrasive agent resulted in significantly greater disease severity than inoculation with a conidial soil drench. The addition of an abrasive agent could simulate wounding caused by blowing soil particles. In Michigan, onion acreage is predominantly located on muck soils. In the field, soil particles in combination with wind can cause wounds on the onion foliage, potentially exacerbating onion leaf and neck anthracnose when the pathogen is present. In potato, wounding of the foliage prior to inoculation with $C$. coccodes

\section{TABLE 2}

Effect of temperature and duration of relative humidity on the area under the disease progress curve (AUDPC) for onion leaf and neck anthracnose severity on Infinity onion seedlings inoculated with Colletotrichum coccodes

Parameter Mean AUDPC

Temperature $\left({ }^{\circ} \mathrm{C}\right)$

15

20

25

30

$7.5 \mathrm{a}^{\mathrm{z}}$

$68.6 \mathrm{a}$

$253.8 \mathrm{~b}$

$305.8 \mathrm{~b}$

Relative humidity (h)

0

12

24

48

72

$6.8 \mathrm{a}^{\mathrm{z}}$

$11.7 \mathrm{a}$

$168.5 \mathrm{~b}$

$271.3 \mathrm{bc}$

$336.3 \mathrm{c}$

${ }^{\mathrm{z}}$ Means within the same parameter for main effect followed by the same letter are not significantly different (LSD), $\alpha=0.05$. resulted in high disease severity (Barkdoll and Davis 1992; Johnson 1994; Johnson and Miliczky 1993; Tsror [Lahkim] and Johnson 2000). In some instances, the incidence and severity of the disease in commercial fields has resulted in premature foliar death when an effective fungicide program was lacking (Hausbeck, personal observation). In this study, onion seedlings at the 4- to 5leaf growth stages were susceptible to $C$. coccodes regardless of the inoculation method when incubated under favorable environmental conditions.

C. coccodes is capable of producing sclerotia, which can survive in the soil and serve as a source of primary inoculum (Sanogo and Pennypacker 1997). Sclerotia geminate and produce mycelium, which can infect plant tissue (debris or living host), and produce acervuli and conidia (Dillard and Cobb 1998; Farley 1976; Sanogo and Pennypacker 1997). In tomatoes and potatoes, C. coccodes was found to be introduced via contaminated seed (Ben-Daniel et al. 2010; Dung et al. 2012; Lees et al. 2010); it is unknown how the pathogen was introduced into the major onion-growing regions in Michigan. Onion roots can become infected by $C$. coccodes (Rodriguez-Salamanca 2013), similar to tomato and potato (Dillard and Cobb 1997, 1998; Lees and Hilton 2003; Nitzan et al. 2006a). In Michigan, microsclerotia were observed on the roots of inoculated onions in a cultivar trial (Rodriguez-Salamanca and Hausbeck, unpublished data). Experiments including C. coccodes sclerotia alone or in association with tomato fruit skin proved that sclerotia alone survived longer compared with sclerotia associated with plant tissue. After five years in the soil, $90 \%$ of the $C$. coccodes sclerotia buried at 10 and $20 \mathrm{~cm}$ below the surface were viable, compared with $55 \%$ of sclerotia at the soil surface (Dillard and Cobb 1998).

To develop management strategies to minimize $C$. coccodes outbreaks, future research could focus on the ability of the pathogen to survive on crops (or debris) and the role soilborne inoculum may serve. Onions in Michigan are planted primarily on organic (muck) soils (Hausbeck 2005), and growers rotate with celery, radishes, field corn, or soybeans (M. Hausbeck, personal communication); only soybean has been reported as a host for $C$. coccodes. However, common weeds may also serve as hosts of $C$. coccodes and can play an important role on the disease/life cycle of the pathogen (Nitzan et al. 2006b; Raid and Pennypacker 1987).

In tomato and pepper, anthracnose severity in the field is associated with high rainfall or overhead irrigation that promotes conidial dispersal and provides leaf wetness conducive to $C$. coccodes germination and infection (Dillard 1989, 1992; Sanogo et al. 1997).

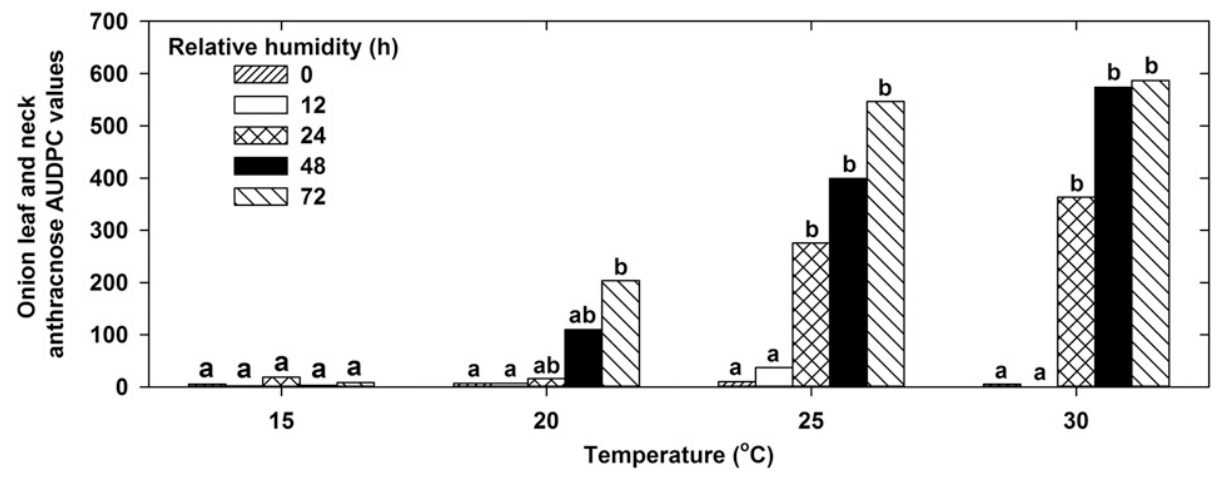

FIGURE 2

Temperature and the duration of high relative humidity interaction on area under the disease progress curve (AUDPC) values of onion leaf and neck anthracnose severity on Infinity onion seedlings inoculated with Colletotrichum coccodes sliced by temperature. Bars within a relative humidity treatment with a letter in common are not significantly different. 
For example, $\geq 10 \mathrm{~h}$ of continuous leaf wetness was needed for C. coccodes conidia to infect tomato fruits (Dillard 1989). Onion anthracnose severity was higher at 25 and $30^{\circ} \mathrm{C}$ when incubated at high $\mathrm{RH}$ for 24,48 , or $72 \mathrm{~h}$. C. coccodes optimal mycelial growth, sporulation, and conidial germination occur at a temperature range of 24 to $28^{\circ} \mathrm{C}$ in vitro (Kendrick and Walker 1948), and optimal lesion development on tomato fruit occurs at a range of 15 to $31^{\circ} \mathrm{C}$ (Dillard 1988, 1989). Similarly, C. coccodes lesions developed in onions when temperatures were at least $20^{\circ} \mathrm{C}$ with a minimum of $24 \mathrm{~h}$ of high RH; a combination of $\geq 24 \mathrm{~h}$ of high $\mathrm{RH}$ and temperatures $\geq 25^{\circ} \mathrm{C}$ was needed for the development of moderate disease severity in Infinity onion seedlings.

According to our results, onion seedlings may not develop symptoms early in the season when temperatures are cooler. In Michigan, onions are direct seeded in late April or May when temperatures can range from 8 to $19^{\circ} \mathrm{C}$ (Anonymous 2010). Our results indicate that optimal anthracnose development could occur in July and August, when average temperatures in Michigan range from 22 to $28^{\circ} \mathrm{C}$ with a maximum of $30^{\circ} \mathrm{C}$ (Anonymous 2010) and overhead irrigation is commonly needed. Incorporating weather variables with the application and timing of efficacious fungicides can help limit this emerging disease in Michigan onion fields.

\section{Acknowledgments}

We thank all the members of the Hausbeck lab for their valuable help.

\section{Literature Cited}

Anonymous. 2010. Enviro-weather Automated Weather Station Network. Michigan State University, Michigan Agricultural Experiment Station. Retrieved January 10, 2011, from https://www.agweather.geo.msu.edu/mawn/ mawn.html.

Anonymous. 2017. Vegetables: 2016 Summary. February 2017. USDA Economics, Statistics and Market Information System, National Agricultural Statistic Service. Online publication. http://usda.mannlib.cornell.edu/usda/ nass/VegeSumm//2010s/2017/VegeSumm-02-22-2017_revision.pdf

Barkdoll, A. W., and Davis, J. R. 1992. Distribution of Colletotrichum coccodes in Idaho and variation in pathogenicity on potato. Plant Dis. 76:131-135.

Ben-Daniel, B., Bar-Zvi, D., and Tsror (Lahkim), L. 2010. Transmission of Colletotrichum coccodes via tomato seeds. Phytoparasitica 38:167-174.

Byrne, J. M., Hausbeck, M. K., and Latin, R. X. 1997. Efficacy and economics of management strategies to control anthracnose fruit rot in processing tomatoes in the Midwest. Plant Dis. 81:1167-1172.

Byrne, J. M., Hausbeck, M. K., Meloche, C., and Jarosz, A. M. 1998. Influence of dew period and temperature on foliar infection of greenhouse-grown tomato by Colletotrichum coccodes. Plant Dis. 82:639-641.

Dillard, H. R. 1988. Influence of temperature, $\mathrm{pH}$, osmotic potential, and fungicide sensitivity on germination of conidia and growth from sclerotia of Colletotrichum coccodes in vitro. Phytopathology 78:1357-1361.

Dillard, H. R. 1989. Effect of temperature, wetness duration, and inoculum density on infection and lesion development of Colletotrichum coccodes on tomato fruit. Phytopathology 79:1063-1066.

Dillard, H. R. 1992. Colletotrichum coccodes: The pathogen and its hosts. Pages 225-236 in: Colletotrichum: Biology, Pathology and Control. J. A. Bailey and M. J. Jeger, eds. C.A.B. International, Wallingford, UK.

Dillard, H. R., and Cobb, A. C. 1997. Disease progress of black dot on tomato roots and reduction in incidence with foliar applied fungicides. Plant Dis. 81: 1439-1442.

Dillard, H. R., and Cobb, A. C. 1998. Survival of Colletotrichum coccodes in infected tomato tissue and in soil. Plant Dis. 82:235-238.
Dung, J. K. S., Ingram, J. T., Cummings, T. F., and Johnson, D. A. 2012. Impact of seed lot infection on the development of black dot and Verticillium wilt of potato in Washington. Plant Dis. 96:1179-1184.

Farley, J. D. 1976. Survival of Colletotrichum coccodes in soil. Phytopathology 66:640-641.

Farr, D. F., and Rossman, A. Y. 2013. Fungal Databases, Systematic Mycology and Microbiology Laboratory, USDA, ARS. Retrieved January 6, 2013, from https://nt.ars-grin.gov/fungaldatabases/.

Hausbeck, M. K. 2005. Pest Management in the Future, a Strategic Plan for the Michigan Onion Industry. USDA Regional IPM Centers, Center Products/PMSPs. Retrieved from https://ipmdata.ipmcenters.org/documents/pmsps/MIonion.pdf.

Hoagland, D. R., and Arnon, D. I. 1950. The water-culture method for growing plants without soil. California Agricultural Experiment Station Circular 347.

Hong, J. K., and Hwang, B. K. 1998. Influence of inoculum density, wetness duration, plant age, inoculation method, and cultivar resistance on infection of pepper plants by Colletotrichum coccodes. Plant Dis. 82:1079-1083.

James, C. 1971. A Manual of Assessment Keys for Plant Diseases. Canada Department of Agriculture publication no. 1458. American Phytopathological Society, Saint Paul, MN.

Johnson, D. A. 1994. Effect of foliar infection caused by Colletotrichum coccodes on yield of Russet Burbank potato. Plant Dis. 78:1075-1078.

Johnson, D. A., and Miliczky, E. R. 1993. Effects of wounding and wetting duration on infection of potato foliage by Colletotrichum coccodes. Plant Dis. 77:13-17.

Kendrick, J. B. J., and Walker, J. C. 1948. Anthracnose of tomato. Phytopathology 38:247-260.

Lees, A. K., Brierley, J. L., Stewart, J. A., Hilton, A. J., Wale, S. J., Gladders, P., Bradshaw, N. J., and Peters, J. C. 2010. Relative importance of seed-tuber and soilborne inoculum in causing black dot disease of potato. Plant Pathol. 59: 693-702.

Lees, A. K., and Hilton, A. J. 2003. Black dot (Colletotrichum coccodes): An increasingly important disease of potato. Plant Pathol. 52:3-12.

Mohan, S. K., Davis, J. R., Sorensen, L. H., and Schneider, A. T. 1992. Infection of aerial parts of potato plants by Colletotrichum coccodes and its effects on premature vine death and yield. Am. Potato J. 69:547-559.

Nitzan, N., Cummings, T. F., and Johnson, D. A. 2008. Disease potential of soiland tuberborne inocula of Colletotrichum coccodes and black dot severity on potato. Plant Dis. 92:1497-1502.

Nitzan, N., Evans, M., and Johnson, D. A. 2006a. Colonization of potato plants after aerial infection by Colletotrichum coccodes, causal agent of potato black dot. Plant Dis. 90:999-1003.

Nitzan, N., Lucas, B. S., and Christ, B. J. 2006b. Colonization of rotation crops and weeds by the potato black dot pathogen Colletotrichum coccodes. Am. J. Potato Res. 83:503-507.

Raid, R. N., and Pennypacker, S. P. 1987. Weeds as hosts for Colletotrichum coccodes. Plant Dis. 71:643-646.

Robert, V., Stegehuis, G., and Stalpers, J. 2005. The MycoBank engine and related databases. http://www.mycobank.org.

Rodriguez-Salamanca, L. M. 2013. Characterization, virulence, epidemiology, and management of Colletotrichum spp. causing anthracnose in onion and celery. Ph.D. dissertation, Michigan State University, East Lansing.

Rodriguez-Salamanca, L. M., Enzenbacher, T. B., Derie, M. L., du Toit, L. J., Feng, C., Correll, J. C., and Hausbeck, M. K. 2012. First report of Colletotrichum coccodes causing leaf and neck anthracnose on onions (Allium cepa) in Michigan. Plant Dis. 96:769.

Sanogo, S., and Pennypacker, S. P. 1997. Factors affecting sporogenic and myceliogenic germination of sclerotia of Colletotrichum coccodes. Plant Dis. 81:333-336.

Sanogo, S., Pennypacker, S. P., Stevenson, R. E., and MacNab, A. A. 1997. Weather variables associated with infection of tomato fruit by Colletotrichum coccodes. Plant Dis. 81:753-756.

Sutton, B. C. 1980. The Coelomycetes: Fungi Imperfecti with Pycnidia Acervuli and Stromata. CABI International, New York, NY.

Tsror (Lahkim), L., and Johnson, D. A. 2000. Colletotrichum coccodes on potato. Pages 362-373 in: Colletotrichum: Host Specificity, Pathology, and Host-Pathogen Interaction. D. Prusky, S. Freeman, and M. B. Dickman, eds. American Phytopathological Society Press, St. Paul, MN. 